4

5

6

7

8

9

\title{
Atlantic Equatorial Undercurrent intensification counteracts warming-induced deoxygenation
}
Peter Brandt ${ }^{1,2}$, Johannes Hahn ${ }^{1}$, Sunke Schmidtko ${ }^{1}$, Franz Philip Tuchen ${ }^{1}$, Robert Kopte ${ }^{3}$, Rainer Kiko ${ }^{1,4}$, Bernard Bourlès ${ }^{5}$, Rena Czeschel $^{1}$, Marcus Dengler ${ }^{1}$

\section{${ }^{1}$ GEOMAR Helmholtz Centre for Ocean Research Kiel, Kiel, Germany}

${ }^{2}$ Faculty of Mathematics and Natural Sciences, Kiel University, Kiel, Germany

${ }^{3}$ Institute of Geosciences, Kiel University, Kiel, Germany

${ }^{4}$ now at Sorbonne Université, Laboratoire d'Océanographie de Villefranche, Villefranche-surMer, France

${ }^{5}$ IRD, Instrumentation, Moyens Analytiques, observations en Géophysique et Océanographie, Plouzané, France 


\section{Introductory paragraph}

The tropical Atlantic upper-ocean circulation experiences multiannual to decadal changes associated with different climate modes and is simultaneously adjusting to climate warming. The most energetic current in the tropical Atlantic is the Equatorial Undercurrent (EUC) flowing eastward along the equator with a core depth of about $80 \mathrm{~m}$ shallowing toward east. Based on long-term moored observations, we show that the EUC strengthened by more than $20 \%$ over the decade 2008-2018. This EUC strengthening is associated with increasing subsurface oxygen concentrations and a thickening of the upper-ocean oxygenated layer in the equatorial Atlantic, thereby counteracting climate warming-induced deoxygenation in this region. The EUC strengthening is found to be mainly forced by trade wind changes in the western tropical North Atlantic. A comprehensive 60-year dataset reveals that the recent oxygen increase in the upper equatorial Atlantic is associated with multidecadal variability characterized by low oxygen concentrations in the 1990s and early 2000s and high oxygen concentrations in the 1960 s and 1970 s. The observed oxygen variability seems to be linked to a compression and expansion of the habitat of tropical pelagic fish and must be accounted for when evaluating possible consequences of deoxygenation for marine ecosystems and fisheries.

Ocean circulation redistributes vast amounts of heat, freshwater and biogeochemical tracers, like nutrients and oxygen, throughout the climate system. It adjusts to climate warming, but at the same time varies with internal modes of natural climate variability. Suggested circulation changes due to climate warming include a strengthening of western boundary currents ${ }^{1,2}$, a weakening of the Atlantic Meridional Overturning Circulation (AMOC) $)^{3,4}$, or a general acceleration of the mean circulation ${ }^{5}$. Globally, the Atlantic Equatorial Undercurrent (EUC) is one of the most energetic currents. It transports thermocline waters eastward along the equator as part of the AMOC and the Subtropical Cells (STCs) ${ }^{6}$. The STCs represent shallow 
overturning circulations involving subduction in the subtropics and upwelling at the equator ${ }^{7,8}$. The EUC strength is only weakly affected by prescribed AMOC changes as shown in forced simulations with constant wind forcing ${ }^{9}$. Instead, decadal variations of the Atlantic EUC detected in a 50-yr run of an assimilation model shows a close correspondence to the decadal variability of the STC strength ${ }^{10}$. Changes in the strength of the EUC may also result from a zonal redistribution of the equatorward pathways associated with the STCs within the thermocline, even without changing the STC strength, as found for the Pacific STCs in global warming simulations ${ }^{11}$. In a high-resolution forced ocean model, an STC weakening in the Pacific Ocean from the 1950 s to the 2000 s is associated with a weakening of the simulated EUC by $20 \%{ }^{12}$. By keeping respiration constant in the model, a severe oxygen decline along the main STC thermocline pathways, including the EUC, is found. By implementing fully interactive biology, the effect of reduced ventilation on oxygen levels is, in turn, largely compensated by the effect of reduced productivity and associated oxygen consumption. A comparison with observed oxygen changes suggests, however, a likely overestimation of the biological effect in the model. The relative importance of the two competing effects remains unclear ${ }^{12}$.

In the upper tropical Atlantic, moored observations have documented seasonal to multiannual variability of the North Brazil Undercurrent ${ }^{13,14}$ and the $\mathrm{EUC}^{15,16}$. Circulation variability on decadal timescales, however, has not been detected in direct current observations so far. Nevertheless, decadal and multidecadal variability of oxygen concentration is well documented ${ }^{17-20}$. It is thought to mainly result from circulation changes that redistribute oxygen in the tropical oceans ${ }^{21-24}$. This oxygen variability is superimposed on the widespread deoxygenation as the global oceanic oxygen content is decreasing since the 1960 s by more than $2 \%{ }^{25}$, thereby contributing to an expansion of the tropical oxygen minimum zones (OMZs). Both effects, internal oxygen variability and deoxygenation due to climate warming, must be accounted for when evaluating changes in low-oxygen regions and the longer-term impact of 
these changes on marine ecosystems and fisheries ${ }^{26}$, in particular the available habitat for tropical pelagic fish ${ }^{27,28}$.

\section{Strengthening of the Atlantic Equatorial Undercurrent}

The velocity field of the EUC has been measured using direct current observations from a large number of research cruises crossing the equator at different longitudes ${ }^{15,29,30}$. Here, we focus on the central equatorial Atlantic at $23^{\circ} \mathrm{W}$, where the EUC starts supplying the equatorial upwelling east of that longitude ${ }^{15}$. The EUC is located between $2^{\circ} \mathrm{S}$ and $1.5^{\circ} \mathrm{N}$ above a depth of $250 \mathrm{~m}$. Its core is at about $80 \mathrm{~m}$ depth and is associated with an oxygen maximum with oxygen levels declining north- and southward from the core latitude close to the equator (Fig. 1b) ${ }^{19}$. Since December 2001, a long-term mooring has been operated almost continuously on the equator at $23^{\circ} \mathrm{W}$ (Fig. 1c, Supplementary Tab. 1) ${ }^{31,32}$. The mooring data have been used to derive an EUC transport time series starting in May $2005^{16}$, here updated to September 2019 (Fig. 1a).

The most prominent signal in the EUC transport time series is a strengthening of the EUC from its lowest values in 2007 to its highest values in 2018 (Fig. 1a). We estimate a ten-year EUC transport increase from August 2008 to July 2018 of 3.3 $\pm 1.6 \mathrm{~Sv}$ decade ${ }^{-1}$. This ten-year trend, which does not substantially change when shifting the examined ten-year period by a few years, corresponds to an increase of the EUC transport of more than $20 \%$ compared to its mean transport of about $14 \mathrm{~Sv}^{16}$.

The time series of eastward velocity anomalies at the equator at $23^{\circ} \mathrm{W}$ shows an eastward velocity increase between about $70 \mathrm{~m}$ and $250 \mathrm{~m}$. A maximum amplitude of nearly $0.2 \mathrm{~m} \mathrm{~s}^{-1}$ decade $^{-1}$ at $100 \mathrm{~m}$ depth can be observed during the period from August 2008 to July 2018 (Fig. 1c, d). Above this layer, observed velocities become increasingly westward during the same period, with the ten-year trend reaching about $-0.1 \mathrm{~m} \mathrm{~s}^{-1}$ decade $^{-1}$. Moored observations at the 
equator at $10^{\circ} \mathrm{W}$ (Supplementary Fig. 1b) generally confirm the existence of a strengthening trend in the eastward velocity at thermocline level in the decade 2008-2018 (Supplementary Fig. 2).

\section{Wind forcing of the circulation variability}

The EUC is predominantly forced by the easterly wind along the equator that establishes an eastward pressure gradient with the sea level sloping downwards toward the east ${ }^{33}$. This local forcing results in an EUC transport variability in accordance with the dominantly multiannual variability of the Atlantic Niño, which is most pronounced in boreal summer ${ }^{34,35}$. Besides the local forcing, the EUC is also forced remotely by easterly winds in the tropics away from the equator driving poleward Ekman transport in both hemispheres. The resulting meridional Ekman transport divergence is directly related to the strength of the STCs and the EUC ${ }^{8,10}$. Typically, this Ekman divergence is quantified by the difference in the meridional Ekman transport across the latitudes $10^{\circ} \mathrm{N}$ and $10^{\circ} \mathrm{S}^{8,36}$.

Meridional Ekman transports derived from different wind products consistently show an increase in the Ekman divergence between $10^{\circ} \mathrm{N}$ and $10^{\circ} \mathrm{S}$ for the decade 2008-2018 (Tab. 1, Fig. 1a, Supplementary Fig. 5). Since the westward wind stress at the equator shows no significant increase (Supplementary Tab. 3), it can be ruled out as a possible forcing of the EUC strengthening. The obtained ten-year trends in the Ekman divergence are, however, generally too small to account for the observed ten-year trend in the EUC transport. Nevertheless, it suggests a strengthening of the Atlantic STCs during the recent decade. Variations between the different wind products are substantial, but within the statistical uncertainties. All wind products suggest that the dominant forcing is in the northern hemisphere associated with a strengthening of the northeast trades (Tab. 1). Further analysis suggests that the wind changes occur

124 dominantly in the western basins, with the eastern basins having only weak or even reversed ten-year trends (Supplementary Fig. 6, Supplementary Tab. 2). 
127 The oxygen distribution along the equator (Fig. 2a) as measured during the recent cruise 128 TRATLEQ 1 (Trans-Atlantic Equatorial cruise 1, Sep./Oct. 2019) is characterized by the presence of an $\mathrm{OMZ}$ in the eastern basin at mid-depth (lowest oxygen concentrations at about $400 \mathrm{~m}$ at $5^{\circ} \mathrm{E}$ off São Tomé). At the western boundary, the energetic North Brazil Current (NBC) transports high-oxygen waters northwestward. After crossing the equator, the NBC partly retroflects into the EUC contributing to the enhanced oxygen levels in the equatorial band ${ }^{37}$. The core of the EUC follows isopycnal surfaces shallowing from west to east (Fig. 2a, c). Water within the EUC core shows decreasing oxygen levels on its way toward the eastern boundary, mainly due to lateral eddy mixing with low-oxygen waters carried westward by the flows to the north and south of the EUC ${ }^{19}$.

The measurements performed in Sep./Oct. 2019 show a specific pattern of elevated oxygen levels with respect to the climatological state of the oxygen distribution estimated for the year 2000 as taken from ${ }^{25}$ (Fig. 2b, see ${ }^{25}$ for details). The largest oxygen increase of more than 20 $\mu \mathrm{mol} \mathrm{kg}-1$ is found in the upper $250 \mathrm{~m}$ east of $10^{\circ} \mathrm{W}$. Generally, enhanced oxygen levels in Sep./Oct. 2019 are found along the whole path of the EUC toward the eastern boundary as well as within the NBC close to the western boundary. The high oxygen levels thus represent a continuation of an oxygenation in the upper equatorial Atlantic estimated for the period 20062018 using oxygen data from a large number of research cruises along $23^{\circ} \mathrm{W}$ in the central equatorial Atlantic (Supplementary Fig. 10a).

The upper-ocean oxygen changes correspond to changes in the thickness of the uppermost oxygenated layer. Here, we define the oxygenated layer thickness (OLT) to be the depth range

148 between the ocean surface and the shallowest depth of the $120 \mu \mathrm{mol} \mathrm{kg}^{-1}$ oxygen surface. While the chosen oxygen level is relatively high with respect to intermediate hypoxias defined elsewhere ${ }^{38}$, it is suitable to describe long-term changes in the near-surface habitat of tropical 
151 pelagic fish ${ }^{28,39}$. The mean OLT in the tropical Atlantic shows a characteristic pattern having small values above the OMZs of the eastern tropical North and South Atlantic and slightly larger values along the equator. At the western boundary and in the subtropics poleward of the OMZs, an extensive oxygenated layer is present (Fig. 3a). Using a comprehensive 60-year oxygen dataset, we provide evidence that the equatorial Atlantic undergoes a substantial multidecadal variability with a particularly large OLT in the 1960s and 1970s and a reduced OLT in the 1990s and 2000s (Fig. 3b). Since approximately 2005, a deepening of the $120 \mu \mathrm{mol}$ $\mathrm{kg}^{-1}$ oxygen surface is observed with largest OLTs occurring in Sep./Oct. 2019. This multidecadal variability that is similarly seen in the subsurface oxygen levels (Fig. 3c)

160 dominates any long-term changes that might be present ${ }^{28}$ and clearly affects trends in the OLT 161 calculated for different time spans, e.g. over the periods 1960-2005 or 1960-2020 162 (Supplementary Fig. 9).

\section{Mechanisms of equatorial Atlantic oxygen variability}

The global oceanic oxygen content has declined since the 1960 s by about $2 \%{ }^{25}$ with notable deoxygenation occurring in the upper tropical ocean (Supplementary Fig. 8). About half of the deoxygenation in the upper $1000 \mathrm{~m}$ is suggested to be the result of changing oxygen solubility due to warming waters ${ }^{25}$. In general, the vertical structure of warming-induced oxygen changes might be more complicated as other effects like increased stratification or poleward migration of outcropping density surfaces might come into play ${ }^{24}$ (see supplementary information). Additionally, the deoxygenation pattern associated with a warming ocean is superimposed by ocean variability on different timescales related to the internal variability of the climate system $^{12,23,40}$. Oxygen observations during the last decades reveal substantial variability in the tropical Atlantic on multiannual to decadal timescales ${ }^{19,23}$. However, large uncertainty exists regarding the mechanisms of decadal oxygen changes. Observed oxygen trends calculated over the last 50 years are largely not in agreement with oxygen trends diagnosed from 
biogeochemical model runs ${ }^{41}$. Depending on the specific model used, projections of subsurface oxygen levels also deviate ${ }^{42}$. The here reported strengthening of the Atlantic STCs and EUC in the decade $2008-2018$ in response to an increased Ekman divergence between $10^{\circ} \mathrm{N}$ and $10^{\circ} \mathrm{S}$ (Fig. 1a) add a so far undescribed mechanism for decadal subsurface oxygen variability in the equatorial Atlantic. The vertical structure of the ten-year velocity trend at the equator at $23^{\circ} \mathrm{W}$ (Fig. 1d) shows that the strengthening of the EUC is associated with an intensifying nearsurface westward flow. The intensified westward flow balances the increased Ekman divergence predominantly occurring in the western basin (Supplementary Fig. 6, Supplementary Tab. 2). Other mechanisms, such as changing STC pathways ${ }^{11}$, may also contribute to the observed strengthening of the EUC at $23^{\circ} \mathrm{W}$.

Here we have shown that the observed strengthening of the EUC is associated with a substantial oxygen increase in the upper equatorial Atlantic (Fig. 2b, Fig. 3c, Supplementary Fig. 10). A quantification of the link between EUC intensification and subsurface oxygenation can be made by the evaluation of the oxygen budget of a subsurface volume (see methods). Estimating the flushing time of a subsurface box $\left(100-200 \mathrm{~m}, 4^{\circ} \mathrm{S}-4^{\circ} \mathrm{N}, 35^{\circ} \mathrm{W}-5^{\circ} \mathrm{W}\right)$ by the intensifying EUC yields a timescale similar to the here reported ten-year period of EUC intensification (Supplementary Fig. 4). This short flushing timescale substantiates the dominant role of the advective oxygen supply by the EUC to the oxygen budget. However, negative feedback mechanisms might dampen the oxygen response to the intensifying inflow of oxygenated EUC waters. These mechanisms may include an oxygen reduction due to changing advection (mean and eddy advection) as well as vertical mixing in response to increasing subsurface oxygen levels. As indicated by model studies, part of the enhanced ventilation might also be compensated by enhanced primary productivity and enhanced oxygen consumption ${ }^{12}$. So far, enhanced productivity in the equatorial Atlantic is not observed ${ }^{43}$. This could indicate that a possible compensation effect due to enhanced productivity is not of the same order as the 
enhanced ventilation. For the eastern tropical North Pacific away from the equator, changes in the biological productivity forced by the trade winds are instead suggested to be responsible for decadal to centennial oxygen changes ${ }^{40}$. According to that mechanism, enhanced trade winds force a shallowing of the thermocline that results in enhanced primary production and respiration and consequently leads to reduced oxygen levels in the thermocline. Such behavior resulting from a similar forcing, i.e. the strengthening or weakening of the trade winds, would imply opposing oxygen changes in different parts of the tropical oceans.

The variability of the northeast trade winds is likely linked to the Atlantic Multidecadal Variability (AMV) changing from its cold phase in the 1970s to its warm phase in the 2000s followed by another cold phase ${ }^{44-46}$. The AMV affects the trade winds in the northern

211 hemisphere, which are weakest during its warm phase ${ }^{47,48}$. While all analyzed wind products

212 generally confirm a strengthening of the Ekman divergence in the decade 2008-2018 (mostly

213 due to the increase in northern hemisphere Ekman transport), its magnitude varies by almost a

214 factor of two (Tab. 1). Similar uncertainties in wind trends for specific periods were obtained 215 when analyzing different reanalysis products ${ }^{49}$. For some wind products it is explicitly stated 216 that they are not well suited for studies of long-term wind trends (e.g. 217 https://climatedataguide.ucar.edu/climate-data/ccmp-cross-calibrated-multi-platform-wind-

218 vector-analysis). Despite the uncertainties in multidecadal wind variability, equatorial oxygen 219 observations reveal a multidecadal cycle of deoxygenation and oxygenation in the equatorial 220 Atlantic (Fig. 3). This cycle is possibly linked to the AMV via its effect on the STCs. This internal variability of the climate system likely impacts marine ecosystems and fisheries in the equatorial Atlantic by compressing and expanding the habitat of tropical pelagic fish ${ }^{28,50}$ on decadal timescales. A better understanding and prediction of locally amplified internal variability, as observed in the equatorial Atlantic, is crucial in order to improve the performance of forced ocean biogeochemistry circulation models. Furthermore, it substantially aids the 
226 evaluation of impacts of climate change induced global deoxygenation on the marine ecosystem

227 and its socioeconomic dependencies. 


\section{References}

2291 Yang, H. et al. Intensification and poleward shift of subtropical western boundary currents in a warming climate. $J$ Geophys Res-Oceans 121, 4928-4945, doi:10.1002/2015jc011513 (2016).

2 Todd, R. E. et al. Global Perspectives on Observing Ocean Boundary Current Systems. Front Mar Sci 6, doi:10.3389/fmars.2019.00423 (2019).

3 Rahmstorf, S. et al. Exceptional twentieth-century slowdown in Atlantic Ocean overturning circulation. Nat Clim Change 5, 475-480, doi:10.1038/Nclimate2554 (2015).

4 Frajka-Williams, E. et al. Atlantic Meridional Overturning Circulation: Observed Transport and Variability. Front Mar Sci 6, doi:10.3389/fmars.2019.00260 (2019).

$5 \quad \mathrm{Hu}, \mathrm{S}$. J. et al. Deep-reaching acceleration of global mean ocean circulation over the past two decades. Sci Adv 6, doi:10.1126/sciadv.aax7727 (2020).

6 Hazeleger, W. \& Drijfhout, S. Subtropical cells and meridional overturning circulation pathways in the tropical Atlantic. J Geophys Res-Oceans 111, doi:10.1029/2005jc002942 (2006).

7 Zhang, D. X., McPhaden, M. J. \& Johns, W. E. Observational evidence for flow between the subtropical and tropical Atlantic: The Atlantic subtropical cells. J Phys Oceanogr 33, 17831797, doi:10.1175/2408.1 (2003).

8 Schott, F. A., McCreary, J. P. \& Johnson, G. C. in Earth Climate: The Ocean-Atmosphere Interaction Geophysical Monograph 147 (eds C. Wang, S.-P. Xie, \& J. A. Carton) 261-304 (American Geophysical Union, 2004).

9 Fratantoni, D. M., Johns, W. E., Townsend, T. L. \& Hurlburt, H. E. Low-latitude circulation and mass transport pathways in a model of the tropical Atlantic ocean. $J$ Phys Oceanogr 30, 1944-1966, doi:Doi 10.1175/1520-0485(2000)030<1944:Llcamt>2.0.Co;2 (2000).

10 Rabe, B., Schott, F. A. \& Kohl, A. Mean circulation and variability of the tropical Atlantic during 1952-2001 in the GECCO assimilation fields. J Phys Oceanogr 38, 177-192, doi:10.1175/2007jpo3541.1 (2008).

11 Luo, Y. Y., Rothstein, L. M. \& Zhang, R. H. Response of Pacific subtropical-tropical thermocline water pathways and transports to global warming. Geophys Res Lett 36, doi:10.1029/2008gl036705 (2009).

12 Duteil, O., Böning, C. W. \& Oschlies, A. Variability in subtropical-tropical cells drives oxygen levels in the tropical Pacific Ocean. Geophys Res Lett 41, 8926-8934, doi:10.1002/2014g1061774 (2014).

13 Schott, F. A. et al. The shallow and deep western boundary circulation of the South Atlantic at $5^{\circ}-11^{\circ}$ S. J Phys Oceanogr 35, 2031-2053, doi:doi:10.1175/JPO2813.1 (2005).

14 Hummels, R. et al. Interannual to decadal changes in the western boundary circulation in the Atlantic at 11 degrees S. Geophys Res Lett 42, 7615-7622, doi:10.1002/2015g1065254 (2015).

15 Johns, W. E. et al. Zonal structure and seasonal variability of the Atlantic Equatorial Undercurrent. Clim Dynam 43, 3047-3069, doi:10.1007/s00382-014-2136-2 (2014).

16 Brandt, P., Funk, A., Tantet, A., Johns, W. \& Fischer, J. The Equatorial Undercurrent in the central Atlantic and its relation to tropical Atlantic variability. Clim Dynam 43, 2985-2997, doi:10.1007/s00382-014-2061-4 (2014).

17 Stramma, L., Johnson, G. C., Sprintall, J. \& Mohrholz, V. Expanding oxygen-minimum zones in the tropical oceans. Science 320, 655-658, doi:10.1126/Science.1153847 (2008).

18 Deutsch, C., Brix, H., Ito, T., Frenzel, H. \& Thompson, L. Climate-Forced Variability of Ocean Hypoxia. Science 333, 336-339, doi:10.1126/Science.1202422 (2011).

19 Brandt, P. et al. On the role of circulation and mixing in the ventilation of oxygen minimum zones with a focus on the eastern tropical North Atlantic. Biogeosciences 12, 489-512, doi:10.5194/bg-12-489-2015 (2015).

20 Montes, E. et al. Decadal variability in the oxygen inventory of North Atlantic subtropical underwater captured by sustained, long-term oceanographic time series observations. Global Biogeochem Cy 30, 460-478, doi:10.1002/2015gb005183 (2016).

21 Ito, T. \& Deutsch, C. Variability of the oxygen minimum zone in the tropical North Pacific during the late twentieth century. Global Biogeochem Cy 27, 1119-1128, doi:10.1002/2013gb004567 (2013). 
22 Duteil, O., Schwarzkopf, F. U., Böning, C. W. \& Oschlies, A. Major role of the equatorial current system in setting oxygen levels in the eastern tropical Atlantic Ocean: A high- resolution model study. Geophys Res Lett 41, 2033-2040, doi:doi:10.1002/2013g1058888 (2014).

23 Hahn, J., Brandt, P., Schmidtko, S. \& Krahmann, G. Decadal oxygen change in the eastern tropical North Atlantic. Ocean Sci 13, 551-576, doi:10.5194/os-13-551-2017 (2017).

24 Oschlies, A., Brandt, P., Stramma, L. \& Schmidtko, S. Drivers and mechanisms of ocean deoxygenation. Nat Geosci 11, 467-473, doi:10.1038/s41561-018-0152-2 (2018).

25 Schmidtko, S., Stramma, L. \& Visbeck, M. Decline in global oceanic oxygen content during the past five decades. Nature 542, 335-339, doi:10.1038/nature21399 (2017).

26 Breitburg, D. et al. Declining oxygen in the global ocean and coastal waters. Science 359, doi:10.1126/science.aam7240 (2018).

27 Leung, S., Thompson, L., McPhaden, M. J. \& Mislan, K. A. S. ENSO drives near-surface oxygen and vertical habitat variability in the tropical Pacific. Environ Res Lett 14, doi:10.1088/1748-9326/ab1c13 (2019).

28 Stramma, L. et al. Expansion of oxygen minimum zones may reduce available habitat for tropical pelagic fishes. Nat Clim Change 2, 33-37, doi:10.1038/Nclimate1304 (2012).

29 Schott, F. A. et al. The zonal currents and transports at 35 degrees $\mathrm{W}$ in the tropical Atlantic. Geophys Res Lett 30, doi:10.1029/2002g1016849 (2003).

30 Kolodziejczyk, N., Bourlès, B., Marin, F., Grelet, J. \& Chuchla, R. Seasonal variability of the Equatorial Undercurrent at 10 degrees $\mathrm{W}$ as inferred from recent in situ observations. J Geophys Res-Oceans 114, doi:10.1029/2008JC004976 (2009).

31 Bourlès, B. et al. PIRATA: A Sustained Observing System for Tropical Atlantic Climate Research and Forecasting. Earth Space Sci 6, 577-616, doi:10.1029/2018ea000428 (2019).

32 Foltz, G. R. et al. The Tropical Atlantic Observing System. Front Mar Sci 6, doi:10.3389/fmars.2019.00206 (2019).

33 Wacongne, S. Dynamical regimes of a fully nonlinear stratified model of the Atlantic Equatorial Undercurrent. J Geophys Res-Oceans 94, 4801-4815, doi:doi:10.1029/JC094iC04p04801 (1989).

34 Chang, P. et al. Climate fluctuations of tropical coupled systems - The role of ocean dynamics. J Climate 19, 5122-5174, doi:10.1175/Jcli3903.1 (2006).

35 Hormann, V. \& Brandt, P. Atlantic Equatorial Undercurrent and associated cold tongue variability. $J$ Geophys Res-Oceans 112, doi:10.1029/2006jc003931 (2007).

36 Tuchen, F. P., Lübbecke, J. F., Schmidtko, S., Hummels, R. \& Böning, C. W. The Atlantic Subtropical Cells Inferred from Observations. $J$ Geophys Res-Oceans, doi:10.1029/2019jc015396 (2019).

37 Schott, F. A., Fischer, J. \& Stramma, L. Transports and pathways of the upper-layer circulation in the western tropical Atlantic. J Phys Oceanogr 28, 1904-1928, doi:10.1175/15200485(1998)028<1904:TAPOTU>2.0.CO;2 (1998).

38 Levin, L. A. Manifestation, Drivers, and Emergence of Open Ocean Deoxygenation. Annual Review of Marine Science, Vol 10 10, 229-260, doi:10.1146/annurev-marine-121916-063359 (2018).

39 Vaquer-Sunyer, R. \& Duarte, C. M. Thresholds of hypoxia for marine biodiversity. P Natl Acad Sci USA 105, 15452-15457, doi:10.1073/pnas.0803833105 (2008).

40 Deutsch, C. et al. Centennial changes in North Pacific anoxia linked to tropical trade winds. Science 345, 665-668, doi:10.1126/Science.1252332 (2014).

41 Stramma, L., Oschlies, A. \& Schmidtko, S. Mismatch between observed and modeled trends in dissolved upper-ocean oxygen over the last 50 yr. Biogeosciences 9, 4045-4057, doi:10.5194/Bg-9-4045-2012 (2012).

42 Bopp, L. et al. Multiple stressors of ocean ecosystems in the 21st century: projections with CMIP5 models. Biogeosciences 10, 6225-6245, doi:10.5194/bg-10-6225-2013 (2013).

43 Rousseaux, C. S. \& Gregg, W. W. Recent decadal trends in global phytoplankton composition. Global Biogeochem Cy 29, 1674-1688, doi:10.1002/2015gb005139 (2015).

44 Zhang, R. \& Delworth, T. L. Simulated tropical response to a substantial weakening of the Atlantic thermohaline circulation. J Climate 18, 1853-1860, doi:Doi 10.1175/Jcli3460.1 (2005).

45 Knight, J. R., Folland, C. K. \& Scaife, A. A. Climate impacts of the Atlantic Multidecadal Oscillation. Geophys Res Lett 33, doi:10.1029/2006g1026242 (2006). 
Frajka-Williams, E., Beaulieu, C. \& Duchez, A. Emerging negative Atlantic Multidecadal

47 Delworth, T. L. \& Mann, M. E. Observed and simulated multidecadal variability in the Northern Hemisphere. Clim Dynam 16, 661-676, doi:DOI 10.1007/s003820000075 (2000).

48 Yuan, T. L. et al. Positive low cloud and dust feedbacks amplify tropical North Atlantic Multidecadal Oscillation. Geophys Res Lett 43, 1349-1356, doi:10.1002/2016g1067679 (2016). 49 Ramon, J., Lledó, L., Torralba, V., Soret, A. \& Doblas-Reyes, F. J. What global reanalysis best represents near-surface winds? $Q J$ Roy Meteor Soc 145, 3236-3251, doi:10.1002/qj.3616 (2019).

50 Hollowed, A. B. et al. Projected impacts of climate change on marine fish and fisheries. Ices $J$ Mar Sci 70, 1023-1037, doi:10.1093/icesjms/fst081 (2013). 
Peter Brandt, GEOMAR Helmholtz-Zentrum für Ozeanforschung Kiel, Düsternbrooker Weg 20, D-24105 Kiel, Germany, E-mail: pbrandt@geomar.de, Tel.: +49 431600 4105, Fax: +49 4316004102

\section{Author Information}

Reprints and permissions information is available at www.nature.com/reprints. The authors declare no competing financial interests. Readers are welcome to comment on the online version of the paper. Correspondence and requests for materials should be addressed to P.B. (pbrandt@geomar.de).

Acknowledgments This study was funded by EU H2020 under grant agreement 817578 TRIATLAS project, by the Deutsche Forschungsgemeinschaft as part of the Sonderforschungsbereich 754 "Climate-Biogeochemistry Interactions in the Tropical Ocean" and through several research cruises with RV Meteor and RV Maria S. Merian and by the Deutsche Bundesministerium für Bildung und Forschung (BMBF) as part of the projects NORDATLANTIK (03F0443B) and RACE-Synthese (03F0824C). R.Ki. was additionally supported by a Make Our Planet Great Again grant of the French Agence Nationale de la Recherche under the "Programme d'Investissements d'Avenir", reference ANR-19-MPGA0012. We thank the captains, crews, scientists, and technical groups involved in the different national and international research cruises to the tropical Atlantic that contributed to collecting shipboard and mooring data, and making them freely available. Part of the velocity and oxygen observations were acquired within the PIRATA project and the CLIVAR TACE program. We would like to thank Dongxiao Zhang and Richard Greatbatch for helpful comments.

Author contributions P.B. designed the long-term measurement program, supervised the data analysis and wrote the first version of the manuscript; J.H. analyzed shipboard sections along 
$37623^{\circ} \mathrm{W}$, S.S. analyzed historical and recent oxygen data, F.P.T. analyzed moored velocity data,

377 R.Ko., F.P.T., J.H. calculated and analyzed EUC transport time series, J.H., F.P.T. analyzed 378 different wind products, R.Ki., B.B., R.C, M.D. contributed additional data and expertise on 379 equatorial ocean dynamics and oxygen changes. All authors discussed the results and wrote the 380 manuscript. 
382 Tab. 1 Ten-year (August 2008 to July 2018) trend in Ekman divergence $\left(10^{\circ} \mathrm{N}-10^{\circ} \mathrm{S}\right)$, northward Ekman transport at $10^{\circ} \mathrm{N}$, and southward Ekman transport at $10^{\circ} \mathrm{S}$ with $95 \%$ 384 confidence interval for different wind products.

\begin{tabular}{|l|c|c|c|}
\hline $\begin{array}{l}\text { Wind } \\
\text { Product }\end{array}$ & $\begin{array}{c}\text { Ekman Divergence } \\
\left(10^{\circ} \mathrm{N}-10^{\circ} \mathrm{S}\right) \\
{\left[\mathrm{Sv}_{\text {decade }}{ }^{-1}\right]}\end{array}$ & $\begin{array}{c}\text { Northward Ekman } \\
\text { Transport across } 10^{\circ} \mathrm{N} \\
{\left[\mathrm{Sv} \mathrm{decade}^{-1}\right]}\end{array}$ & $\begin{array}{c}\text { Southward Ekman } \\
\text { Transport across } 10^{\circ} \mathrm{S} \\
{\left[\mathrm{Sv}_{\text {decade }}{ }^{-1}\right]}\end{array}$ \\
\hline ASCAT & $2.0 \pm 1.2$ & $1.5 \pm 1.2$ & $0.4 \pm 0.6$ \\
\hline CCMP & $1.1 \pm 1.2$ & $1.0 \pm 1.1$ & $0.1 \pm 0.6$ \\
\hline JRA55-do & $1.5 \pm 1.0$ & $1.3 \pm 1.0$ & $0.2 \pm 0.7$ \\
\hline
\end{tabular}

385 

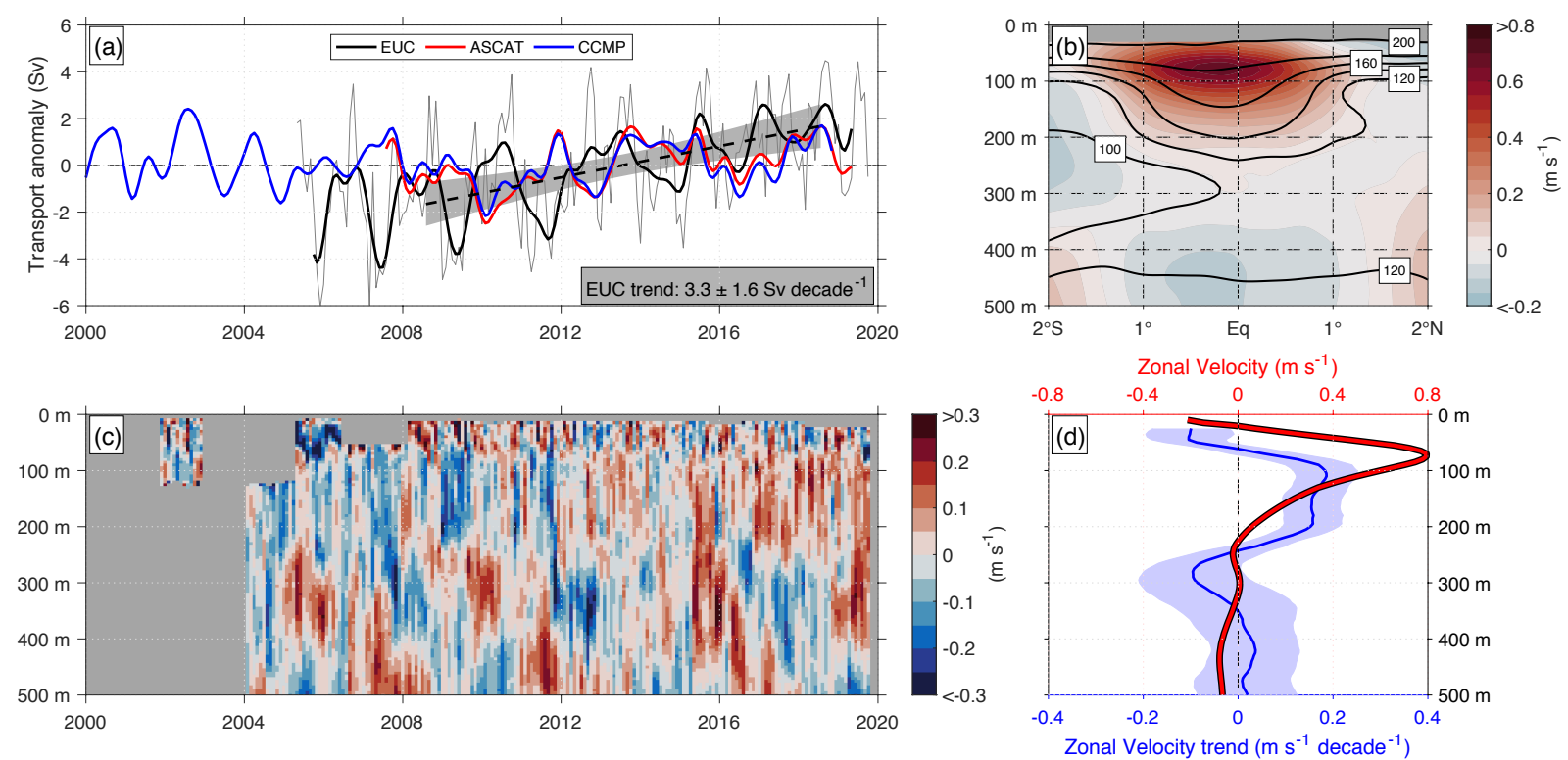

Fig. 1 The Atlantic Equatorial Undercurrent (EUC) at $23^{\circ} \mathbf{W}$. a, EUC transport anomaly

(monthly data, grey thin line; mean and annual and semi-annual harmonics subtracted and 270-

391 day low-pass filtered, black thick line; ten-year (August 2008 to July 2018) trend, black dashed

392 line; with 95\% confidence interval, grey shading) and STC transport anomaly calculated from

393 Ekman divergence between $10^{\circ} \mathrm{N}$ and $10^{\circ} \mathrm{S}$ using different wind forcing products (ASCAT, red;

394 CCMP, blue; mean and annual and semi-annual harmonics subtracted and 270-day low-pass

395 filtered). b, Mean eastward velocity (color) and dissolved oxygen ( $\mu \mathrm{mol} \mathrm{kg}^{-1}$, contours) from

396 shipboard measurements after ${ }^{19}$. c, Time series of eastward velocity anomaly at the equator

397 with mean and seasonal cycle subtracted. d, Ten-year (August 2008 to July 2018) trend in

398 eastward velocity (blue, with 95\% confidence interval, light blue shading) and mean eastward

399 velocity (red) at the equator. 

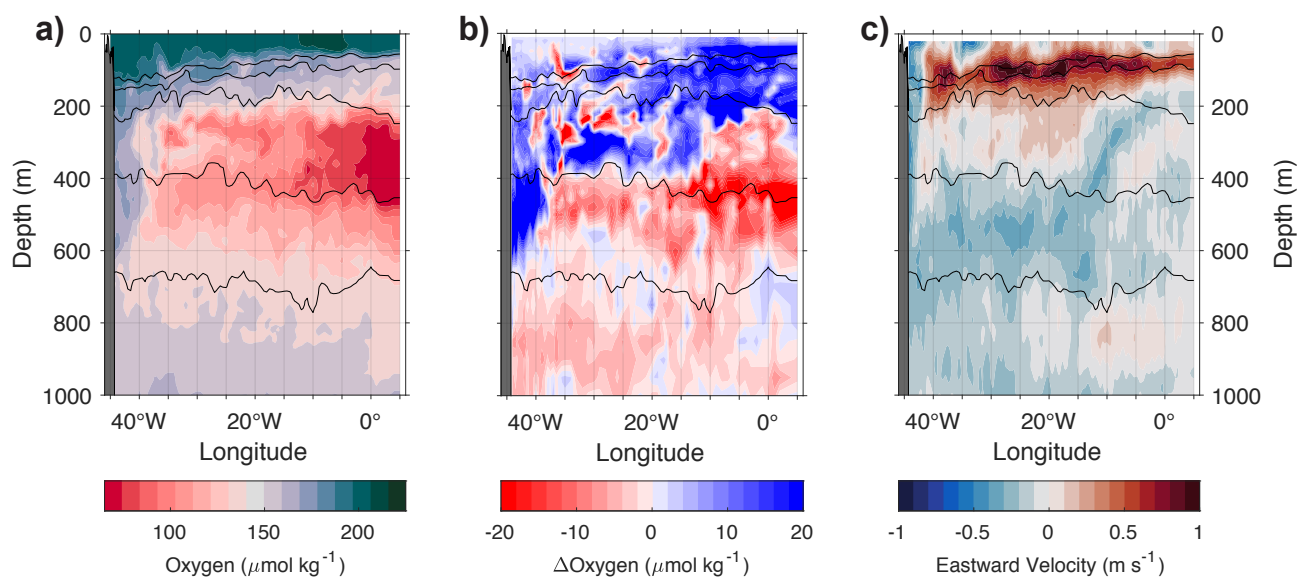

402 Fig. 2 Shipboard measurements along the Atlantic equator in Sep./Oct. 2019. a, Dissolved

403 oxygen concentration. b, Dissolved oxygen anomaly relative to the climatological year-2000

404 state $^{25}$. c, Eastward velocity. Grey areas mark bottom topography at the western boundary.

405 Black lines mark the $25 \mathrm{~kg} \mathrm{~m}^{-3}, 26 \mathrm{~kg} \mathrm{~m}^{-3}, 26.5 \mathrm{~kg} \mathrm{~m}^{-3}, 27 \mathrm{~kg} \mathrm{~m}^{-3}$ and $27.25 \mathrm{~kg} \mathrm{~m}^{-3}$ isopycnals. 
a)

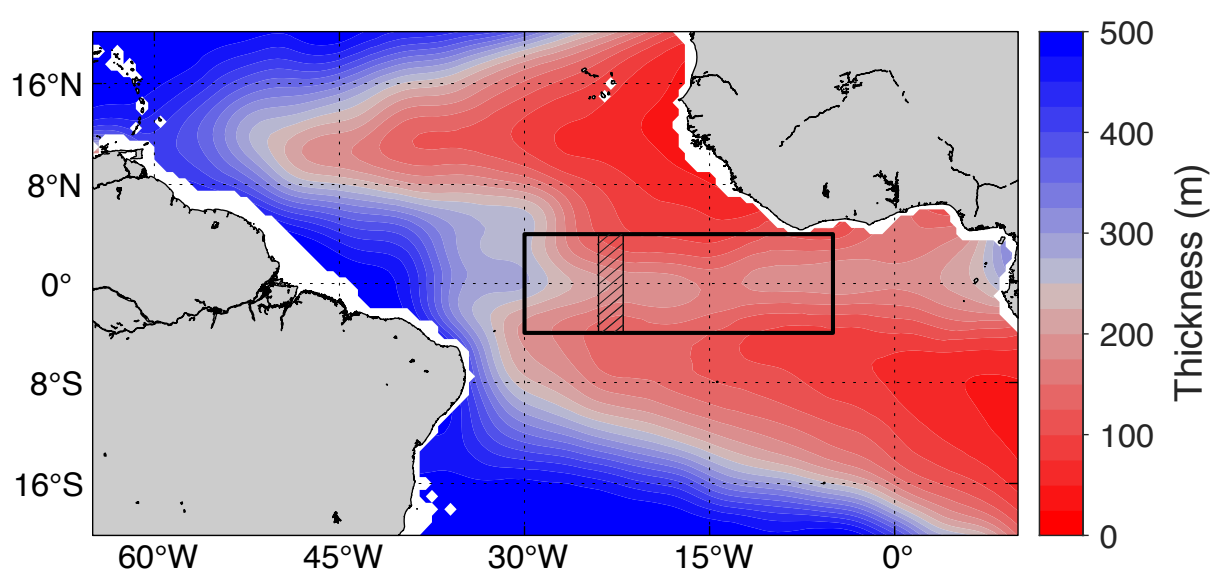

b)
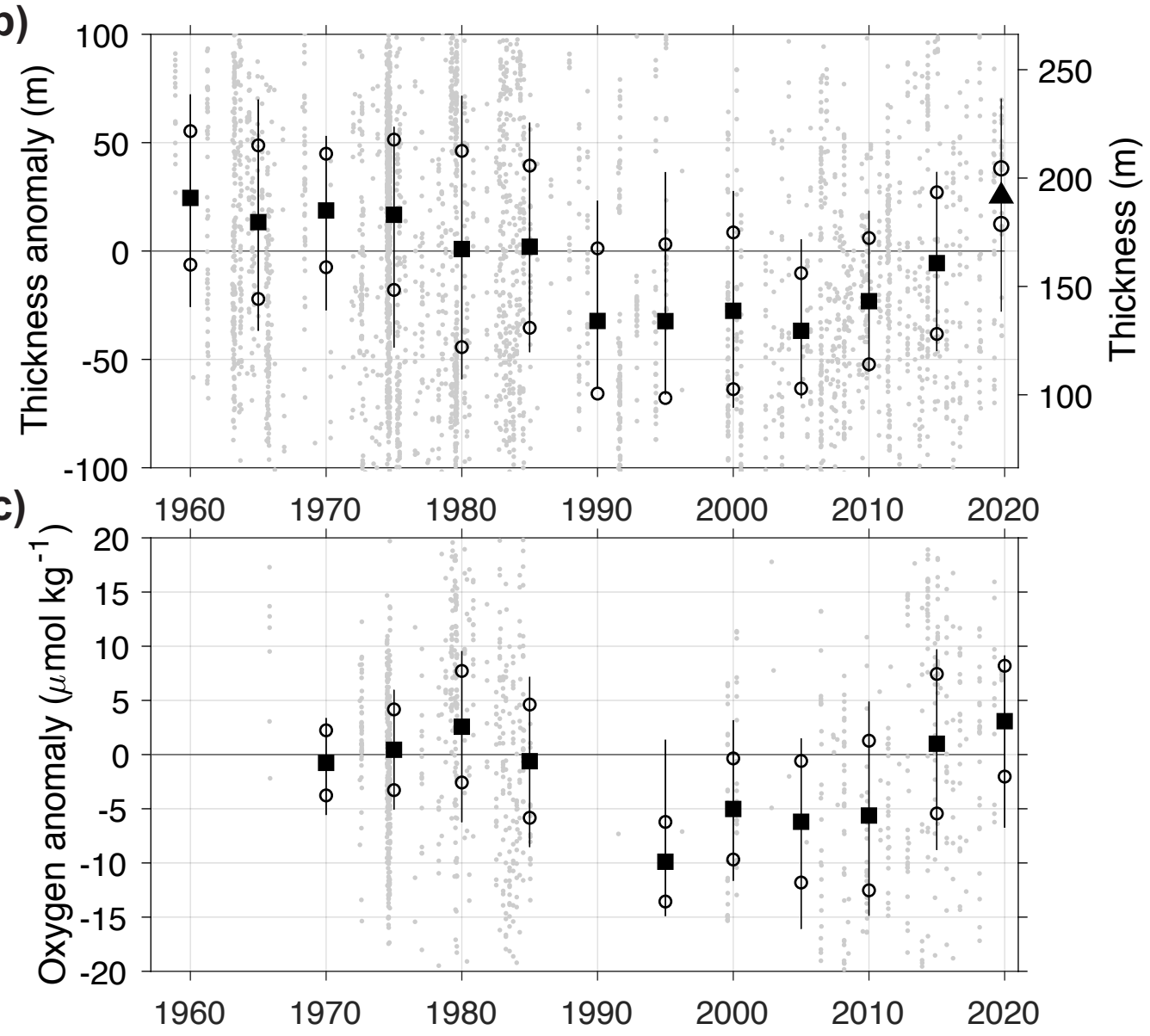

409 Fig. 3 Surface oxygenated layer thickness (OLT) in the tropical Atlantic. a, Mean OLT. b,

410 Time series of OLT anomaly in the equatorial region $\left(35^{\circ} \mathrm{W}-5^{\circ} \mathrm{W}, 4^{\circ} \mathrm{S}-4^{\circ} \mathrm{N}\right)$ marked in (a). c,

411 Time series of the oxygen anomaly in the box $100-200 \mathrm{~m}, 24^{\circ} \mathrm{W}-22^{\circ} \mathrm{W}, 4^{\circ} \mathrm{S}-4^{\circ} \mathrm{N}$ marked in (a)

412 by the hatched area. Indicated in (b) and (c) are the ten-year median anomalies (black squares), 
413 the probable error of the median derived from the median absolute deviation (open circles), as

414 well as the corresponding interquartile range (black lines) of the individual data anomalies (grey

415 dots). The triangle marks the median anomaly of data taken in Sep./Oct. 2019. OLT is defined

416 by the depth range between ocean surface and shallowest depth of the $120 \mu$ mol $\mathrm{kg}^{-1}$ oxygen

417 surface.

418 
420 We use different observational datasets from moored and shipboard measurement programs

421 (particularly from cruise TRATLEQ 1, RV Meteor cruise M158 in September/October 2019), different wind products, and historical oxygen data within this study.

\section{Moored velocity data}

Velocity data from the equator at $23^{\circ} \mathrm{W}$ (Fig. 1c) were acquired using moored acoustic Doppler current profilers (ADCPs). They cover the whole depth range of the EUC for most of the 12 to 18 months long consecutive mooring periods except for a few years at the beginning ${ }^{31}$. All velocities were detided using a 40-h low-pass filter and subsampled to $12-\mathrm{h}$ intervals. The oceanic variability on short timescales (i.e. during a single mooring period) clearly exceeds the measurement accuracy of the different instruments. Errors in ADCP compass calibration are expected to be unsystematic for the different instruments used, not able to produce an artificial eastward velocity trend for a ten-year period that encompasses several, typically 1.5-year long mooring periods. Similar trends in northward velocity are substantially smaller and not significant. Moored velocity data from the equator at $10^{\circ} \mathrm{W}$ were acquired by single upward looking ADCPs. Data treatment was the same as for the $23^{\circ} \mathrm{W}$ moored velocity data.

\section{EUC transport}

For five years as part of the Tropical Atlantic Climate Experiment (TACE), i.e. from mid-2006 to mid-2011, additional moorings were installed at $0^{\circ} 45^{\prime} \mathrm{N}$ and $0^{\circ} 45^{\prime} \mathrm{S}$ to obtain a well-defined EUC transport time series. The EUC transport was obtained using variability patterns derived from shipboard observations that were regressed onto the moored time series. Error estimates

440 of these calculations are given as RMS differences ${ }^{16}$. The EUC transport based on three 441 moorings (RMS difference of $0.79 \mathrm{~Sv}$ ) was used to validate the reconstruction of the EUC transport using only the central mooring (RMS difference of $1.29 \mathrm{~Sv}$ ), which was the only 
mooring operated from mid-2011 onwards ${ }^{16}$. The EUC transport represents the integral of the eastward velocity, $\mathrm{u}$, with $\mathrm{u}>0$ of the reconstructed sections over latitude and depth within the domain covering $30-300 \mathrm{~m}$ depth and $1^{\circ} 12^{\prime} \mathrm{S}-1^{\circ} 12^{\prime} \mathrm{N}$. The EUC transport is characterized by substantial intraseasonal variability of $2.3 \mathrm{~Sv}$ (standard deviation of 8-to-90-day band-pass filtered data), a seasonal cycle of $1.2 \mathrm{~Sv}$ (standard deviation of the monthly mean seasonal cycle), and multiannual variability of $1.1 \mathrm{~Sv}$ (standard deviation of detrended time series with annual and semi-annual harmonics subtracted and 270-day low-pass filtered).

To test the sensitivity of the ten-year trend of the EUC transport to the used definition, we have calculated different versions of the EUC transport: Version 1) only positive $\mathrm{u}, 30-300 \mathrm{~m}$ and $1^{\circ} 12^{\prime} \mathrm{S}-1^{\circ} 12^{\prime} \mathrm{N}$ (as we used in the manuscript), Version 2) positive and negative $\mathrm{u}, 30-300 \mathrm{~m}$ and $1^{\circ} 12^{\prime} \mathrm{S}-1^{\circ} 12^{\prime} \mathrm{N}$ and Version 3 ) positive and negative $\mathrm{u}, 30-200 \mathrm{~m}$ and $1^{\circ} \mathrm{S}-1^{\circ} \mathrm{N}$. The area in version 3 was reduced in order to avoid most areas with westward velocities. All three versions show a clear increase in the EUC transport (Supplementary Fig. 3). Version 2 shows the strongest intensification, which is due to the fact that areas with westward velocities additionally decrease during EUC intensification. Version 3 shows the smallest increase, which is due to the fact that part of the EUC is missing, when shrinking the area. In summary, the estimated ten-year trend of the EUC transport that we present in the manuscript is more on the conservative side of possible estimates.

\section{Shipboard measurements during TRATLEQ 1}

Salinity, temperature, depth, oxygen $\left(\mathrm{CTD}-\mathrm{O}_{2}\right)$ measurements during TRATLEQ 1 were carried out with a Seabird Electronics (SBE) 9plus system that was equipped, in addition to its own pressure sensor, with two parallel sensor sets for temperature, conductivity, and oxygen (Supplementary Tab. 4). The oxygen measurements were calibrated against Winkler-titrated oxygen from discrete water samples. For the calibration a linear correction polynomial depending on pressure, temperature and the actual oxygen value was fitted. A total of 403 


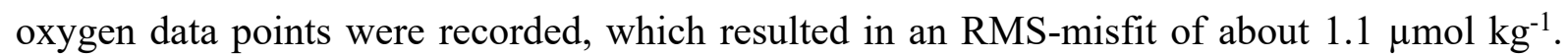
Velocities along the equator during TRATLEQ 1 were measured by two vessel-mounted ADCP systems (Supplementary Tab. 4). A 75-kHz RDI Ocean Surveyor mounted in the ship's hull provided the velocity distribution in the upper $650 \mathrm{~m}$ with a vertical resolution of $8 \mathrm{~m}$. The second instrument, a 38-kHz RDI Ocean Surveyor installed in the sea chest, had a measurement range of at least $1000 \mathrm{~m}$ at a vertical resolution of $32 \mathrm{~m}$. Both datasets were vertically linearly interpolated on a $10-\mathrm{m}$ grid and then combined with a linear weight transition for $75-\mathrm{kHz}: 38$ $\mathrm{kHz}$ velocities of 5:1 in the upper $350 \mathrm{~m}$ depth, $3: 1$ in the depth range between 350 and $500 \mathrm{~m}$ depth and 1:1 below $500 \mathrm{~m}$ depth. The combined dataset was then mapped onto a common grid of $0.2^{\circ} \times 10 \mathrm{~m}$ resolution using Gaussian mapping scales with a horizontal half width scale of $0.2^{\circ}$ and cut-off scale of $0.6^{\circ}$ and vertical mapping scales of $8 \mathrm{~m}$ for half width and $16 \mathrm{~m}$ for cut-off. The data were horizontally linearly interpolated between $2.6^{\circ} \mathrm{E}$ and $5^{\circ} \mathrm{E}$ to fill the data gap.

\section{Ekman transport from different wind products}

The Ekman transport was calculated from different wind products. The meridional Ekman volume transport per unit length $\left[\mathrm{Sv} \mathrm{m}^{-1}\right]$ is

$$
T_{E k, y}=\frac{\tau_{x}}{\rho_{0} f}
$$

with $\tau_{x}$ the eastward wind stress, $\rho_{0}$ water density (taken here to be $1025 \mathrm{~kg} \mathrm{~m}^{-3}$ ) and $f$ the Coriolis parameter. Following ${ }^{51}, \tau_{x}$ is calculated using the $10-\mathrm{m}$ wind vector, $\vec{v}_{10}$, and the 10 m eastward wind component, $u_{10}$

$$
\tau_{x}=\rho_{a i r} c_{D} u_{10}\left|\vec{v}_{10}\right|
$$

with $\rho_{\text {air }}$ air density (taken here to be $1.223 \mathrm{~kg} \mathrm{~m}^{-3}$ ) and $c_{D}$ drag coefficient for neutrally stable conditions ${ }^{52}$ 


$$
c_{D}=\left(\frac{2.70}{\left|\vec{v}_{10}\right|}+0.142+0.0764\left|\vec{v}_{10}\right|\right) \times 10^{-3}
$$

492 The meridional Ekman transport [Sv] through $10^{\circ} \mathrm{N}$ and $10^{\circ} \mathrm{S}$ was eventually calculated by 493 zonal integration of $T_{E k, y}$ along the respective latitudes between the western and eastern 494 boundaries. The Ekman divergence [Sv] was calculated as the difference between the 495 meridional Ekman transport through $10^{\circ} \mathrm{N}$ and $10^{\circ} \mathrm{S}$. Annual and semi-annual cycles were 496 calculated for the same period, that was used for the ten-year trend calculation (2008-2018), 497 and subsequently removed from the whole time series. Derived time series were then 270-day 498 low-pass filtered.

\section{Trend calculation and significance}

500 Linear trends presented in this study were obtained from a linear regression of a time series of 501 limited length. The $95 \%$ confidence interval was calculated following ${ }^{53}$ as product of the estimated standard deviation of the trend and the t-score of the Student's t-distribution for 95\% significance and $n-2$ degrees of freedom, where $n$ is the number of independent values used for the linear regression. $\mathrm{n}$ was estimated from the autocorrelation functions for the different time series, which revealed an average decorrelation scale of 6 months for time series with annual and semi-annual cycles removed and 270-day low-pass filtered to remove seasonal and shorter period variability. Hence, the trend calculations were evaluated based on 6-months averages. The trend errors of Ekman transports and divergences do not account for possible biases

509 inherent in the different wind products. However, differences in the trends derived from 510 different wind products provide an estimate of the uncertainty.

\section{Oxygen data and analysis}

512 All used oxygen data are listed in Supplementary Tab. 5. Duplicates were avoided by using the

513 first profile in the combined dataset within $24 \mathrm{~h}$ and $5 \mathrm{~km}$ to all others. For each used profile 
514 the uppermost depth of the $120 \mu \mathrm{mol} \mathrm{kg}^{-1}$ oxygen surface was determined by linear vertical 515 interpolation. The climatological mean state of this oxygen surface was then computed by a 516 least squares model on a $0.5^{\circ} \times 0.5^{\circ}$ grid. For each grid point to be mapped all data within a 517 radius of $1200 \mathrm{~km}$ are used by applying a Gaussian weighting using a half folding width of 275

$518 \mathrm{~km}$. Prior to the mapping a linear gradient in latitude and longitude as well as a quadratic fit in 519 latitude was subtracted from the original data. An absolute minimum weight of 0.01 was applied 520 to the Gaussian weighting to take the larger distribution and horizontal gradients of the depth 521 of the $120 \mu \mathrm{mol} \mathrm{kg}^{-1}$ oxygen surface better into account. For each profile the depth anomaly of 522 the $120 \mu \mathrm{mol} \mathrm{kg}{ }^{-1}$ oxygen surface compared to the local climatological mean was derived. All anomalies within the equatorial box $\left(35^{\circ} \mathrm{W}-5^{\circ} \mathrm{W}, 4^{\circ} \mathrm{S}-4^{\circ} \mathrm{N}\right)$ were used to derive a monthly

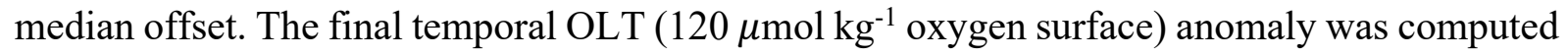
by the median of all anomalies within 10 years, corrected by the monthly offset.

To verify the statistical significance of the median we compute the median absolute deviation (MAD) as a robust measure of the variability of the sample, in addition to the interquartile range. The probable error of the median as derived from the MAD as provided in Fig. $3 \mathrm{~b}$ and $3 \mathrm{c}$ is calculated as follows. The MAD is defined as the median of all deviation from the median. Assuming a normal distribution we get the probable error by multiplying the MAD with 1.4826 54.

532 For a detailed description of the data handling of historical data including the stability of oxygen measurements and the likelihood of systematic biases as well as a verification of the mapping 534 bias the reader is referred to ${ }^{25}$. Modern oxygen data since 2006 are validated by a crossover analysis for all recent data ${ }^{55}$. The accuracy of oxygen data taken during cruises since 2006

536 (Supplementary Tabs. 4 and 6) is estimated to be better than $2 \mu \mathrm{mol} \mathrm{kg}^{-1}$ as derived from the 537 calibration with the Winkler titration method. 
To provide a more quantitative view on the link between EUC intensification and oxygenation, we specifically focus on the layer between 100 and $200 \mathrm{~m}$ depth that contains in most places the mean depth of the $120 \mu \mathrm{mol} \mathrm{kg}{ }^{-1}$ oxygen surface (Fig. 3). Here, we want to provide some bulk estimates for oxygen changes and volume flushing rates. To relate the OLT estimated in the region $35^{\circ} \mathrm{W}-5^{\circ} \mathrm{W}, 4^{\circ} \mathrm{S}-4^{\circ} \mathrm{N}$ (Fig. $3 \mathrm{~b}$ ) to oxygen changes in the layer $100-200 \mathrm{~m}$, it is most convenient to look at the $23^{\circ} \mathrm{W}$ section, which provides best data coverage (Supplementary Fig. 7). Taking oxygen data presented in Fig. $3 \mathrm{c}$ representing the box $100-200 \mathrm{~m}, 24^{\circ} \mathrm{W}-22^{\circ} \mathrm{W}, 4^{\circ} \mathrm{S}-$ $4^{\circ} \mathrm{N}$, we find an oxygen decrease of $-1.7 \pm 0.6 \mu \mathrm{mol} \mathrm{kg}^{-1} \mathrm{decade}^{-1}$ for the period 1960-2004 and an oxygen increase of $+9.5 \pm 1.8 \mu \mathrm{mol} \mathrm{kg}^{-1}$ decade $^{-1}$ for the period 2005-2020. This variability of the subsurface oxygen concentration is in general agreement with the thinning and thickening of the surface oxygenated layer during the corresponding periods found in the region $35^{\circ} \mathrm{W}$ $5^{\circ} \mathrm{W}, 4^{\circ} \mathrm{S}-4^{\circ} \mathrm{N}$ (Fig. 3b).

The main oxygen supply to the box $100-200 \mathrm{~m}, 4^{\circ} \mathrm{S}-4^{\circ} \mathrm{N}, 35^{\circ} \mathrm{W}-5^{\circ} \mathrm{W}$ is via the EUC. However, how much the intensification of the EUC during the period August 2008 to July 2018 did contribute to the oxygen increase depends not only on the EUC inflow, but similarly on the EUC outflow at the eastern boundary of the box, other inflows and outflows such as associated with the different branches of the South Equatorial Current as well as on the remaining terms of the oxygen budget. Formally the volume integrated oxygen budget can be written as follows:

$$
\int_{V} \frac{\partial O}{\partial t} d V=V \frac{\partial O_{B o x}}{\partial t}=\oint_{\partial V}(O \vec{u}) \cdot \vec{n} d S+R
$$

where $V$ is the box volume, $O$ is oxygen, $t$ is time, $O_{B o x}$ is the mean oxygen concentration in the box, $\vec{u}$ is the velocity vector, $\partial V$ is the boundary of the volume and $\vec{n}$ the inward normal vector to $\partial V$. Mass conservation requires $\oint_{\partial V} \vec{u} \cdot \vec{n} d S=0$ or the inflow into the box must equal the outflow out of the box. The residuum, $R$, includes all other budget terms, particularly lateral 
eddy fluxes, diapycnal mixing, and oxygen consumption that all might change for an intensifying EUC and increasing oxygen concentration.

While we have provided an estimate of the temporal change of the mean box oxygen concentration by calculating the oxygen change along $\sim 23^{\circ} \mathrm{W}$ (Fig. $3 \mathrm{c}$ ), the other budget terms are largely unknown. However, we can give an estimate of the oxygen supply into the box due to the EUC. For the climatological mean state, we can write the volume integrated oxygen budget as follows:

$$
0=\oint_{\partial V}\left(O_{c} \vec{u}_{c}\right) \cdot \vec{n} d S+R_{c}
$$

where $O_{c}$ is the climatological oxygen concentration, $\vec{u}_{c}$ is the climatological velocity vector, and $R_{c}$ is the climatological residuum that balances the oxygen transport divergence in a climatological mean state. Here, we can approximate the mean advective oxygen supply by the climatological EUC as $O_{i n} T_{0}$, where $O_{i n}$ is the temporal mean, transport-weighted oxygen concentration of the climatological EUC with transport $T_{0}$. An intensification of the EUC would result in a flushing of the box volume with excess EUC waters that, in case of a complete flushing and no other damping terms, would increase the mean box oxygen concentration by $O_{i n}-O_{B o x, 0}$, with $O_{B o x, 0}$ being the mean oxygen concentration in the box at the time, $t_{0}$, when the EUC intensification starts.

The flushing time, $t_{f l u s h}$, can be estimated as

$$
\int_{t_{0}}^{t_{0}+t_{f l u s h}}\left(T-T_{0}\right) d t=V
$$
where $T$ is the EUC transport. Here, we can only calculate the EUC transport time series at $23^{\circ} \mathrm{W}$, which is not at the western boundary of our box. However, the EUC at $23^{\circ} \mathrm{W}$ is a direct continuation of the EUC arriving at $35^{\circ} \mathrm{W}$ and can serve as a good approximation of the 
increasing EUC oxygen supply. The transport-weighted mean oxygen concentration of the EUC flow at $23^{\circ} \mathrm{W}, 100-200 \mathrm{~m}, 1.2^{\circ} \mathrm{S}-1.2^{\circ} \mathrm{N}$ that can be derived from Fig. $1 \mathrm{~b}$ is $153 \mu \mathrm{mol} \mathrm{kg}{ }^{-1}$. It is thus substantially higher than the mean oxygen concentration in the box estimated at $23^{\circ} \mathrm{W}$, $100-200 \mathrm{~m}, 4^{\circ} \mathrm{S}-4^{\circ} \mathrm{N}$ to be $120 \mu \mathrm{mol} \mathrm{kg}{ }^{-1}$. The EUC transport at $23^{\circ} \mathrm{W}$ in that layer before the EUC intensification (averaged between August 2005 and July 2008) is 5.4 Sv (Supplementary Fig. 4a). For the excess transport due to the intensifying EUC, $T-T_{0}$, a flushing time of the box volume can be estimated to be about 10 years (Supplementary Fig. 4b). Note that the flushing time of the box volume by the climatological EUC transport, $T_{0}$, is only 1.7 years. The excess EUC transport is thus strong enough to potentially exchange the whole box volume during about the period of EUC intensification discussed here. However, due to several negative feedback mechanisms, the mean box oxygen concentration will not reach the oxygen level of the inflowing EUC. Among the negative feedback mechanisms are an increasing oxygen concentration of the outflow (that is part of the term $\oint_{\partial V}(O \vec{u}) \cdot \vec{n} d S$ ) as well as a changing residuum, R. The latter include processes like enhanced lateral oxygen eddy fluxes out of the box and reduced diapycnal oxygen flux into the box from above due to changed lateral and vertical oxygen gradients, respectively, all associated with an increasing mean oxygen concentration in the box. Changes in consumption could occur as well, e.g., associated with an enhanced nutrient supply of the equatorial upwelling by the EUC intensification, enhanced biological production and consequently enhanced consumption due to heterotrophic respiration of sinking biological material. However, these terms of the oxygen budget cannot be meaningfully quantified with the observational data at hand.

\section{Data and code availability}

All data supporting the findings of this study are publicly available as referenced within the paper and in the supplementary material (Supplementary Tabs. 1, 4, and 5). All necessary 
608 code for the data analysis and preparation of the figures of this manuscript is freely available

609 at https://doi.org/10.5281/zenodo.4436007.

610

\section{References}

612

613

51 Risien, C. M. \& Chelton, D. B. A Global Climatology of Surface Wind and Wind Stress Fields from Eight Years of QuikSCAT Scatterometer Data. J Phys Oceanogr 38, 2379-2413, 615 doi:10.1175/2008jpo3881.1 (2008).

61652 Large, W. G., Mcwilliams, J. C. \& Doney, S. C. Oceanic Vertical Mixing - a Review and a 617 Model with a Nonlocal Boundary-Layer Parameterization. Rev Geophys 32, 363-403, 618

619

620

621

622

623

624 doi:10.1029/94rg01872 (1994).

53 von Storch, H. \& Zwiers, F. W. Statistical Analysis in Climate Research. (Cambridge University Press, 2001).

54 Rousseeuw, P. J. \& Croux, C. Alternatives to the Median Absolute Deviation. J Am Stat Assoc 88, 1273-1283, doi:Doi 10.2307/2291267 (1993).

55 Olsen, A. et al. GLODAPv2.2019-an update of GLODAPv2. Earth Syst Sci Data 11, 1437 1461, doi:10.5194/essd-11-1437-2019 (2019).

625

626 